\title{
Effects of Vanadium Content on Structure and Chemical State of TiVN Films Prepared by Reactive DC Magnetron Co-Sputtering
}

\author{
Teerawit Deeleard $^{1,3}$, Surasing Chaiyakun ${ }^{2,3 *}$, Artorn Pokaipisit ${ }^{3}$, Pichet Limsuwan ${ }^{1,3}$ \\ ${ }^{1}$ Department of Physics, Faculty of Science, King Mongkut's University of Technology Thonburi, Bangkok, Thailand; ${ }^{2}$ Vacuum \\ Technology and Thin Film Research Laboratory, Department of Physics, Faculty of Science, Burapha University, Chonburi, Thai- \\ land; ${ }^{3}$ Thailand Center of Excellence in Physics, Commission on Higher Education, Bangkok, Thailand. \\ Email: opticslaser@yahoo.com, s-chaikhun@hotmail.com
}

Received July $12^{\text {th }}, 2013$; revised August $11^{\text {th }}, 2013$; accepted August $22^{\text {nd }}, 2013$

Copyright (C) 2013 Teerawit Deeleard et al. This is an open access article distributed under the Creative Commons Attribution License, which permits unrestricted use, distribution, and reproduction in any medium, provided the original work is properly cited.

\begin{abstract}
TiVN films were deposited on $\mathrm{Si}(100)$ wafers without external heating and biasing by reactive dc magnetron co-sputtering. Titanium and vanadium metals were used as sputtering targets. Ar and $\mathrm{N}_{2}$ gases were used as sputtering gas and reactive gas, respectively. The flow rates of Ar and $\mathrm{N}_{2}$ were 8 and $4 \mathrm{sccm}$, respectively. The Ti sputtering current $\left(\mathrm{I}_{\mathrm{Ti}}\right)$ was kept constant at $0.6 \mathrm{~A}$ and $\mathrm{V}$ sputtering current $\left(\mathrm{I}_{\mathrm{V}}\right)$ was varied from 0.4 to 1.0 A. The deposition time for all the deposited films was $30 \mathrm{~min}$. The effects of $\mathrm{V}$ sputtering current on the structure, surface and cross-sectional morphologies, and chemical composition and chemical state of the films were investigated by X-ray diffraction (XRD), atomic force microscopy (AFM) and field emission scanning electron microscopy (FE-SEM), and X-ray photoelectron spectroscopy (XPS), respectively. It was found that all the prepared film formed (Ti,V)N solid solution. The lattice parameter was found to decrease while crystallite size, RMS roughness and film thickness increased with increasing $\mathrm{V}$ sputtering current. High resolution XPS spectra of the Ti 2p, V 2p and N 1s revealed that the fraction of Ti-N and V-N bonds increased as the V sputtering current increased. However, the V-N bond was observed only at a high V sputtering current.
\end{abstract}

Keywords: TiVN Film; Solid Solution; DC Magnetron Co-Sputtering

\section{Introduction}

Ternary transition metal nitrides have been attracting great interest for applications as hard protective coating materials due to their high hardness, good wear resistance and excellent corrosion protection [1-3]. In the past two decades, Ti-based ternary nitrides such as $(\mathrm{Ti}, \mathrm{Al}) \mathrm{N}$ [4-6], (Ti,Zr)N [4,7], (Ti,V)N [4,8] and (Ti,Nb)N [9] have been extensively investigated. In recent years, $\mathrm{Cr}-$ based ternary nitrides such as $(\mathrm{Ti}, \mathrm{Cr}) \mathrm{N}$ [10-13], $(\mathrm{Cr}, \mathrm{Al}) \mathrm{N}$ [14-18], (Cr, Zr)N [2,3], (Cr,Si) [19] and (Cr,W)N [20] have been gaining greater attention.

However, only a few studies on $(\mathrm{Ti}, \mathrm{V}) \mathrm{N}$ have been reported in the literature. Konig [21] reported on the deposition of VTiN film on cemented carbide tools by magnetron sputtering. The structure, wear resistance test and performance in cutting test were also reported. Hase-

${ }^{*}$ Corresponding author. gawa et al. [4] deposited (Ti,V)N film on cemented carbide by the ion plating method and investigated on microhardness, lattice parameter and morphology. Ichimiya et al. [8] deposited $(\mathrm{Ti}, \mathrm{V}) \mathrm{N}$ films on WC-Co substrates using the cathodic arc ion plating method and reported on the structure, hardness and cutting performance of the films. In this paper, we report the effects of vanadium sputtering current on the structure, surface morphology, chemical composition and chemical state of TiVN films deposited by reactive de magnetron co-sputtering.

\section{Experiment}

\subsection{Films Preparation}

TiVN films were deposited on $\mathrm{Si}(100)$ wafers without additional heating and biasing of the substrates by a home-made reactive dc magnetron co-sputtering system. Before loading the substrates into the vacuum chamber, 
they were washed by trichloroethylene, acetone and isopropyl alcohol using ultrasonic cleaner each sequentially for $10 \mathrm{~min}$ and then dried by purging of nitrogen. Titanium (99.97\%) and vanadium (99.97\%) metals were used as sputtering targets. Ar (99.99\%) and $\mathrm{N}_{2}$ (99.99\%) gases were used as sputtering gas and reactive gas, with the flow rates of 8 and $4 \mathrm{sccm}$, respectively. The target to substrate distance for both targets was $13 \mathrm{~cm}$. A diffusion pump accompanied with a rotary pump was used to achieve the base pressure of $5.0 \times 10^{-5} \mathrm{mbar}$. Prior to each deposition, the targets were presputtered for $5 \mathrm{~min}$ in order to remove the contaminants from the target surfaces. The Ti sputtering current was kept constant at 0.6 A while V sputtering current was varied from 0.4 to 1.0 A. The deposition conditions for TiVN coatings are summarized in Table 1.

\subsection{Characterization}

The crystalline structure of the TiVN films was investigated by X-ray diffraction (XRD: Rigaku, Rint 2000) using $\mathrm{CuK} \alpha$ radiation operated at $40 \mathrm{kV}$ and $40 \mathrm{~mA}$. The XRD patterns were recorded at grazing incidence angle of $3^{\circ}$ in the $2 \theta$ range of $20^{\circ}$ to $80^{\circ}$ with a scanning rate of $2 \%$ min. The crystallite size was determined from Scherrer's formula. The surface roughness was observed by atomic force microscopy (AFM: Veeco Instrument, Nanoscope IV) in a scanning area of $1 \times 1 \mu \mathrm{m}^{2}$. The crosssectional morphology was investigated using field emission scanning electron microscopy (FE-SEM: Hitachi, S-4700).

The atomic concentration of elements of TiVN films was determined by X-ray photoelectron spectrometry (XPS: Kratos, AXIS Ultra DLD). The quantitative analysis was carried out by a wide scan spectrum of the film surface. Before spectrum acquisition, the film surface area of $2 \times 2 \mathrm{~mm}^{2}$ was cleaned by $\mathrm{Ar}^{+}$ions with an energy of $4 \mathrm{keV}$ and a current of $50 \mu \mathrm{A}$ for $60 \mathrm{sec}$ to remove contaminants. Then, the film surface area of $300 \times$ $700 \mu \mathrm{m}^{2}$ was excited by monochromatic Al K $\alpha$ X-ray with a photon energy of $1486.6 \mathrm{eV}$. The photoelectrons emitted from the film surface were analyzed by a hemispherical analyzer with a pass energy of $80 \mathrm{eV}$. The energy range of the spectrum recording was $0-1200 \mathrm{eV}$. During the XPS analysis, the working pressure was maintained at $6.67 \times 10^{-7} \mathrm{~Pa}$. After background substraction, the peak areas of Ti $2 p, V 2 p, N$ 1s and O 1s core levels were used to determine the atomic concentrations of these elements.

\section{Results and Discussion}

\subsection{Crystalline Structure}

Figure 1 shows the XRD patterns of the TiVN films de-
Table 1. Deposition conditions for TiVN coatings.

\begin{tabular}{cc}
\hline Deposition parameters & Details \\
\hline Targets & $\mathrm{Ti}(99.97 \%), \mathrm{V}(99.97 \%)$ \\
Substrate & $\mathrm{Si}(100)$ \\
Base pressure (mbar) & $5 \times 10^{-5}$ \\
Target to substrate distance (cm) & 13 \\
Deposition time (min) & 30 \\
Ar flow rate (sccm) & 8 \\
$\mathrm{~N}_{2}$ flow rate (sccm) & 4 \\
Ti sputtering current, $\mathrm{I}_{\mathrm{Ti}}$ (A) & 0.6 \\
V sputtering current, $\mathrm{I}_{\mathrm{V}}$ (A) & $0.4,0.6,0.8,1.0$ \\
\hline
\end{tabular}

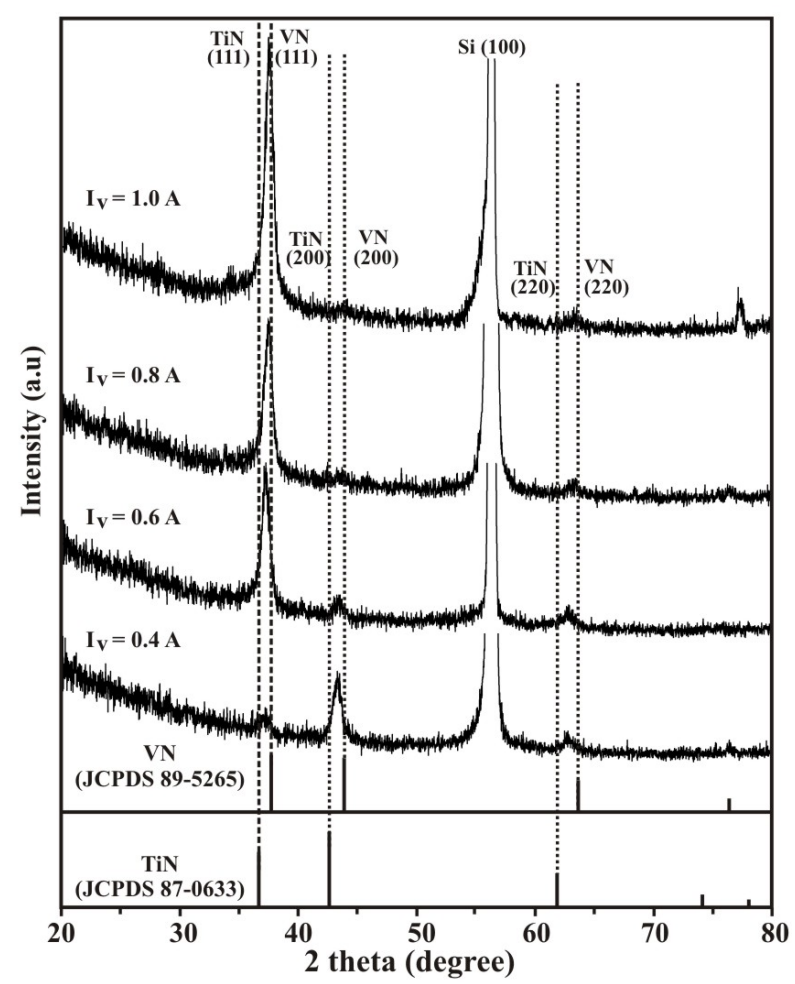

Figure 1. XRD patterns of the TiVN films.

posited at various $\mathrm{V}$ sputtering currents of $0.4,0.6,0.8$ and 1.0 A. Reference peaks of fcc B 1 type structure of TiN and VN were marked according to JCPDS file numbers $87-0633$ and $89-5265$, respectively. It was clearly observed that the diffraction peaks of TiVN located between the peak positions of TiN and $\mathrm{VN}$ suggesting that all the prepared TiVN films exhibited crystalline structure of fcc that similar to the lattice structure of TiN and VN. The TiVN films show strong (111) preferred orienttation. Moreover, the (111) peak intensity increased with increasing $\mathrm{V}$ sputtering current indicating the increase in crystallinity and thickness of the films. 
It was also observed that the position of diffraction peaks gradually shifted toward the higher diffraction angles as the V sputtering current increased. This result led to the decrease in lattice parameter from 0.418 to 0.416 $\mathrm{nm}$ for (111) peak when the V sputtering current was increased from 0.4 to $1.0 \mathrm{~A}$ as shown in Figure 2. The lattice parameter (a) was determined using Bragg's law and the plane-spacing equation, $a=d_{h k l} \sqrt{h^{2}+k^{2}+l^{2}}$ and the results are given in Table 2. The decrease in lattice parameter indicated that $\mathrm{Ti}$ atoms with a larger atomic radius $\left(\mathrm{r}_{\mathrm{Ti}}=0.140 \mathrm{~nm}\right)$ were replaced by smaller $\mathrm{V}$ atoms $\left(r_{\mathrm{V}}=0.135 \mathrm{~nm}\right)$ and $(\mathrm{Ti}, \mathrm{V}) \mathrm{N}$ solid solution was formed

The crystallite size of the films was determined from the Scherrer's formula. The crystallite size obtained from (111) peak is given in Table 2. It is seen that the crystallite size increased from 20.13 to $23.99 \mathrm{~nm}$ corresponding to the increase in intensity of (111) peak.

\subsection{Surface and Cross-Sectional Morphologies}

Figure 3 shows AFM surface images of the TiVN films deposited at various $\mathrm{V}$ sputtering currents of $0.4,0.6$ and $1.0 \mathrm{~A}$. The average root-mean-square (RMS) roughness of TiVN films was determined from AFM images in a selected area of $1 \times 1 \mu \mathrm{m}^{2}$ and the results are given in Table 2. It was observed that the RMS roughness increased from 3.73 to $6.45 \mathrm{~nm}$ as the $\mathrm{V}$ sputtering current was increased from 0.4 to $1.0 \mathrm{~A}$.

Figure 4 shows FE-SEM cross-sectional images of the

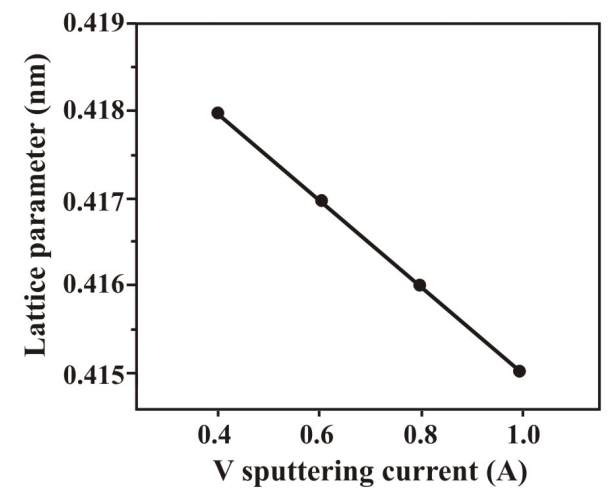

Figure 2. Lattice parameter as a function of $\mathrm{V}$ sputtering current.

Table 2. Various parameters of the TiVN films deposited at differents $I_{V}$.

\begin{tabular}{ccccc}
\hline $\mathrm{I}_{\mathrm{V}}(\mathrm{A})$ & $\begin{array}{c}\text { Lattice parameter } \\
(\mathrm{nm})\end{array}$ & $\begin{array}{c}\text { Crystallite size } \\
(\mathrm{nm})\end{array}$ & $\begin{array}{c}\text { Roughness } \\
(\mathrm{nm})\end{array}$ & $\begin{array}{c}\text { Thickness } \\
(\mathrm{nm})\end{array}$ \\
\hline 0.4 & 0.418 & 20.13 & 3.73 & 267 \\
0.6 & 0.417 & 20.97 & 4.85 & 335 \\
0.8 & 0.416 & 22.38 & 5.33 & 404 \\
1.0 & 0.415 & 23.99 & 6.45 & 461 \\
\hline
\end{tabular}
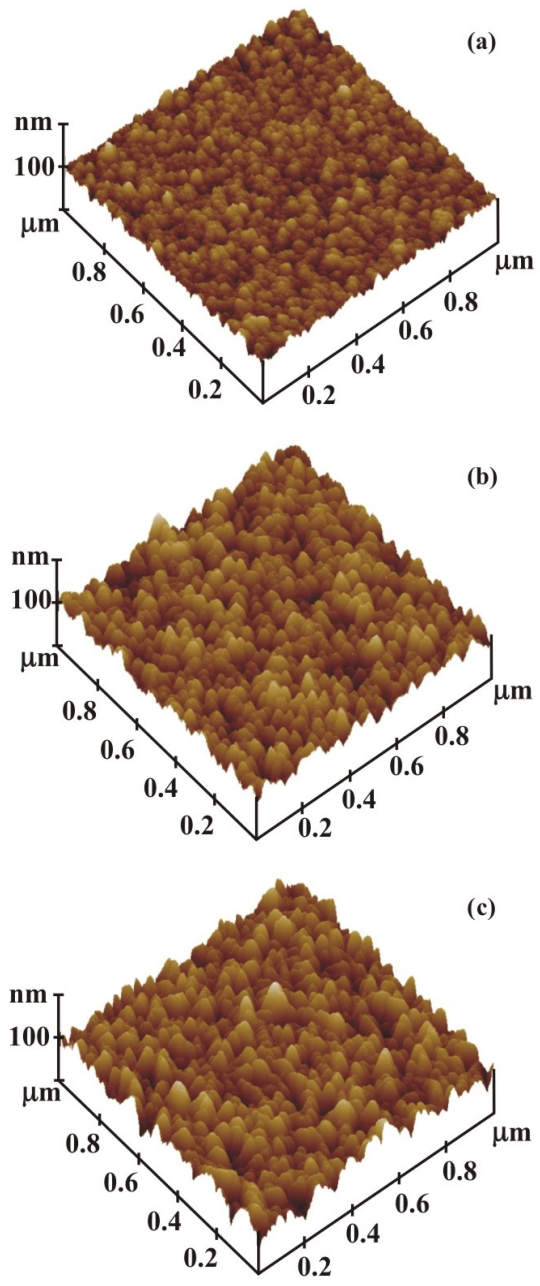

Figure 3. AFM of surfaces morphology of the TiVN films deposited at $\mathrm{V}$ sputtering currents of: (a) 0.4 , (b) 0.6 and (c) 1.0 A.

TiVN films. All the films show columnar structure which corresponded to the Zone 2 in the Thornton's structure zone model. It was observed that as the $\mathrm{V}$ sputtering current increased, the columnar width increased and resulted in the increase of the lateral grain size. This result is in good agreement with XRD result as discussed earlier in previous section. The thicknesses of the films as determined from the images in Figure $\mathbf{4}$ are given in Table 2. It was observed that the thickness of the films increased from 267 to $461 \mathrm{~nm}$ when V sputtering current was increased from 0.4 to $1.0 \mathrm{~A}$ corresponding to the increase in intensity of (111) peak.

\subsection{Chemical Composition}

Table 3 shows the atomic concentration of elements of the TiVN films as investigated by XPS. The V content ( $\mathrm{x}$ value) and $\mathrm{N}$ content (y value) are also given in Table 3. It is seen that the $\mathrm{V}$ content increased from 0.31 to 0.65 

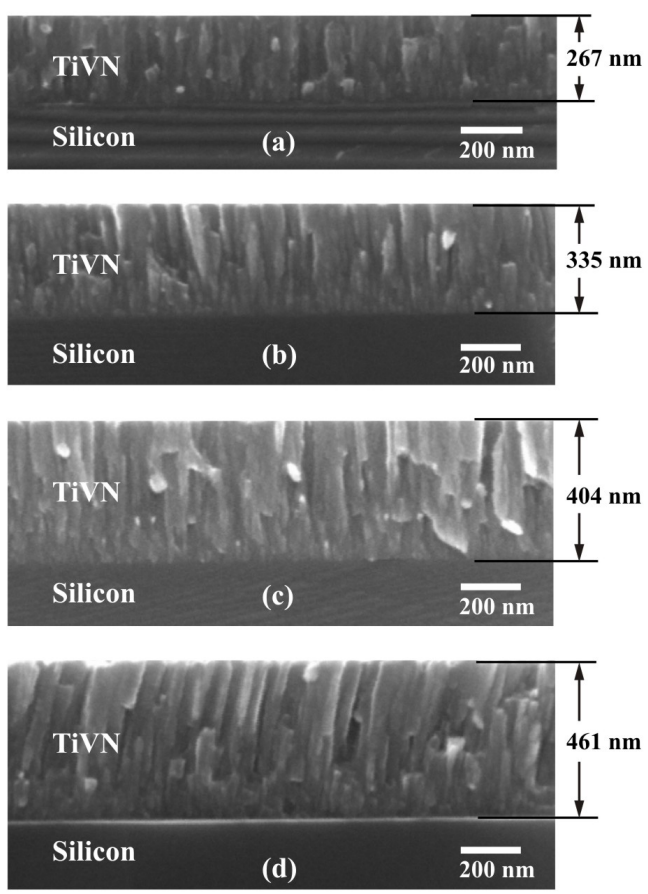

Figure 4. Cross-sectional FE-SEM morphology of the TiVN films deposited at different $\mathrm{V}$ sputtering currents of: (a) 0.4, (b) 0.6, (c) 0.8 and (d) $1.0 \mathrm{~A}$.

Table 3. Chemical composition, $V$ content ( $x$ value) and $N$ content ( $y$ value) in TiVN films as a function of the $V$ sputtering current $\left(\mathrm{I}_{\mathrm{V}}\right)$.

\begin{tabular}{ccccccc}
\hline \multirow{2}{*}{$\mathrm{I}_{\mathrm{V}}(\mathrm{A})$} & \multicolumn{5}{c}{ Concentration (at.\%) } & \multicolumn{2}{c}{$\mathrm{T}=\mathrm{V} /(\mathrm{Ti}+\mathrm{V}) \mathrm{y}=\mathrm{N} /(\mathrm{Ti}+\mathrm{V})$} \\
\cline { 2 - 7 } & $\mathrm{Ti}$ & $\mathrm{V}$ & $\mathrm{N}$ & $\mathrm{O}$ & & \\
\hline 0.4 & 26.96 & 12.38 & 50.48 & 10.18 & 0.31 & 1.28 \\
0.6 & 22.69 & 16.54 & 50.65 & 10.12 & 0.42 & 1.29 \\
0.8 & 17.95 & 21.23 & 50.58 & 10.24 & 0.54 & 1.29 \\
1.0 & 13.66 & 25.52 & 50.05 & 10.77 & 0.65 & 1.28 \\
\hline
\end{tabular}

when the $\mathrm{V}$ sputtering current was increased from 0.4 to $1.0 \mathrm{~A}$ whereas the $\mathrm{N}$ content remained constant at a value of approximately 1.28. The constant of $\mathrm{N}$ content in the films is due to the low $\mathrm{N}$ affinity of $\mathrm{V}$ atom that led to less incorporation of $\mathrm{N}$ atoms in the films [22]. The $\mathrm{N} /(\mathrm{Ti}$ $+\mathrm{V})$ ratio is more than 1 suggested that all the films prepared in this study showed over-stoichiometry. It is noted that oxygen (approx. 10 at.\%) is present in all films. It is possibly due to residual oxygen in the XPS chamber and the exposure of the films to the air ambient before the XPS analysis.

Figure 5 shows the high resolution XPS core level spectra of the Ti 2 p, V $2 p$ and N 1s of the TiVN films deposited at different $V$ sputtering currents. The raw XPS spectra of the Ti $2 p, V 2 p$ and $N$ 1s in Figure 5 were fitted using the Gaussian profile to obtain smooth curves.
Then, the smooth curves were deconvoluted using the Gaussian curve fit after applying Shirley-type background substraction to extract the chemical bonds. Figure 6 shows the deconvolution spectra of Ti $2 p_{3 / 2}, V 2 p_{3 / 2}$
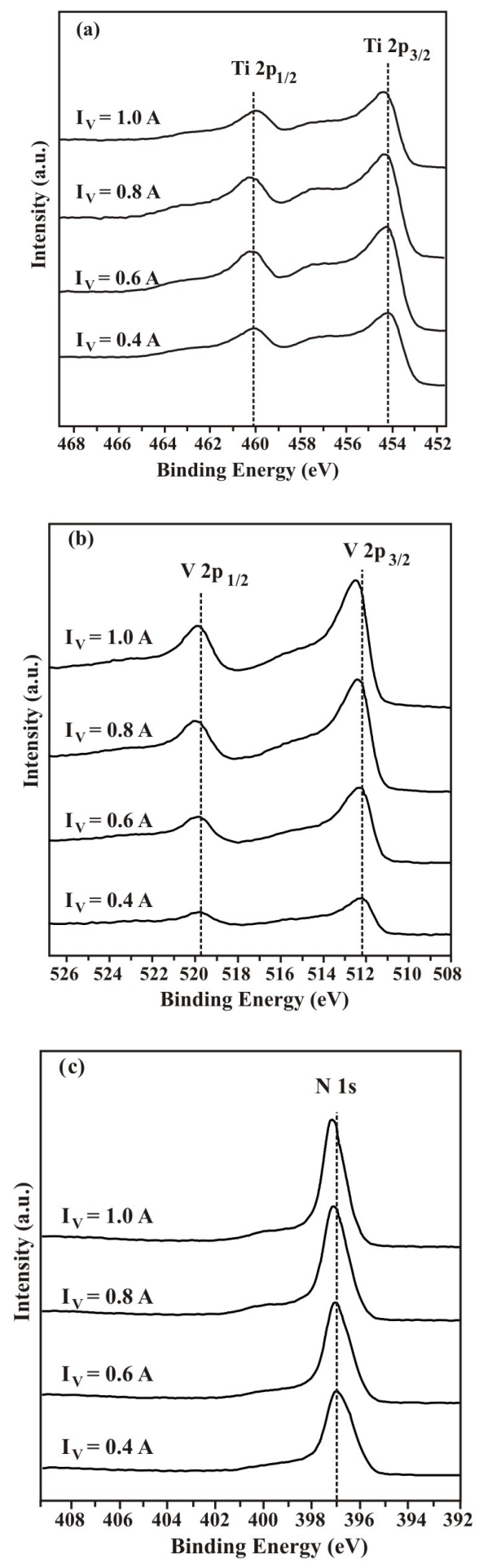

Figure 5. XPS spectra of: (a) Ti 2p, (b) V 2p and (c) N 1s of the TiVN films. 


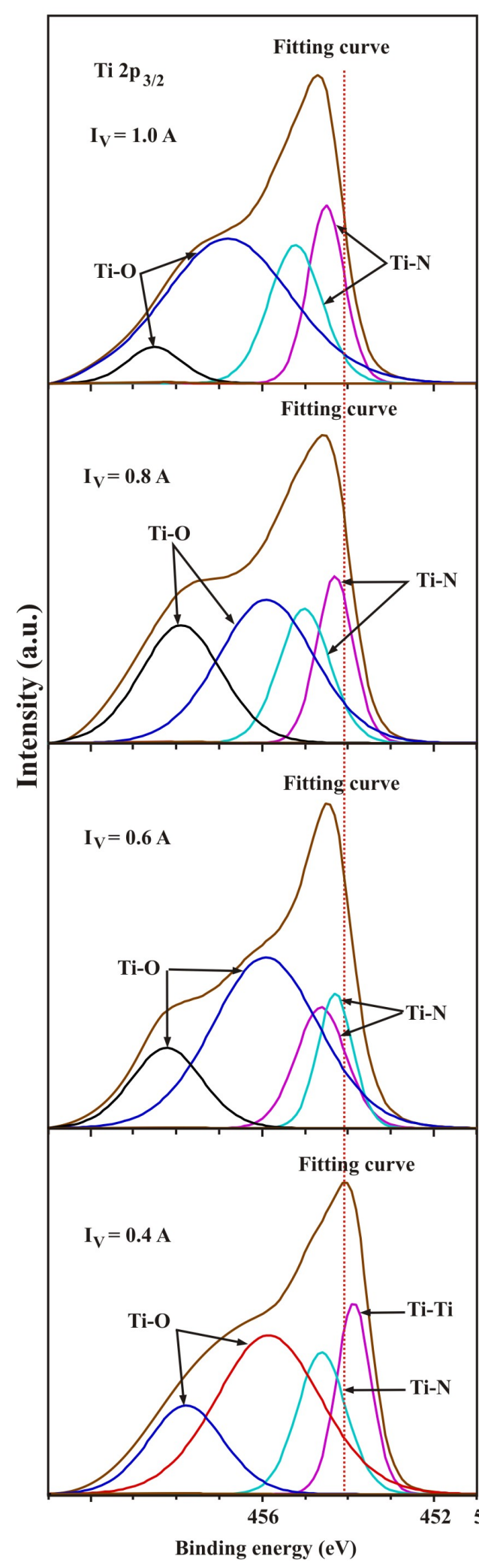

(a)

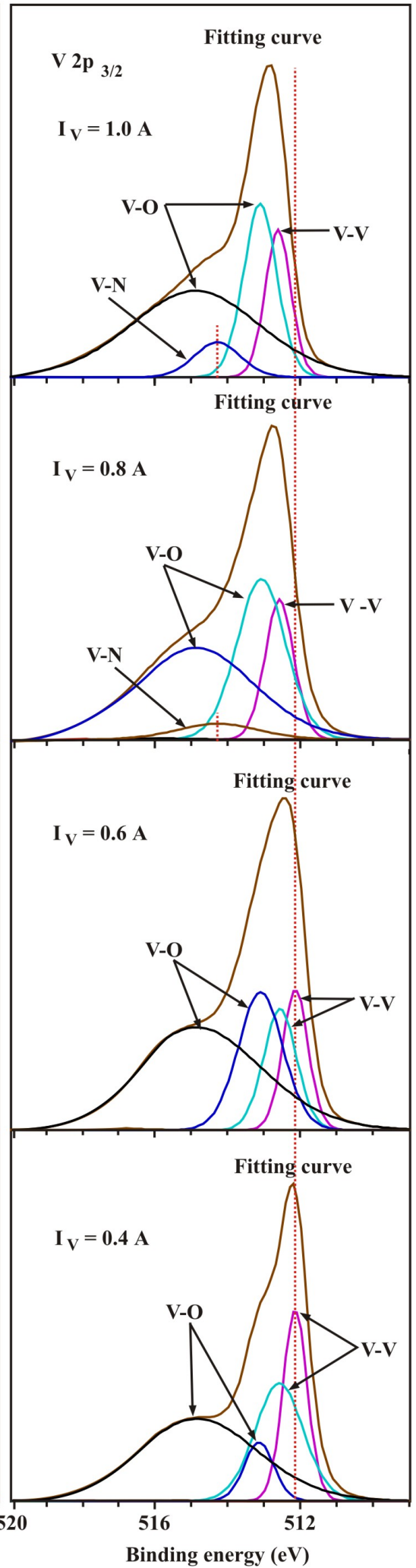

(b)

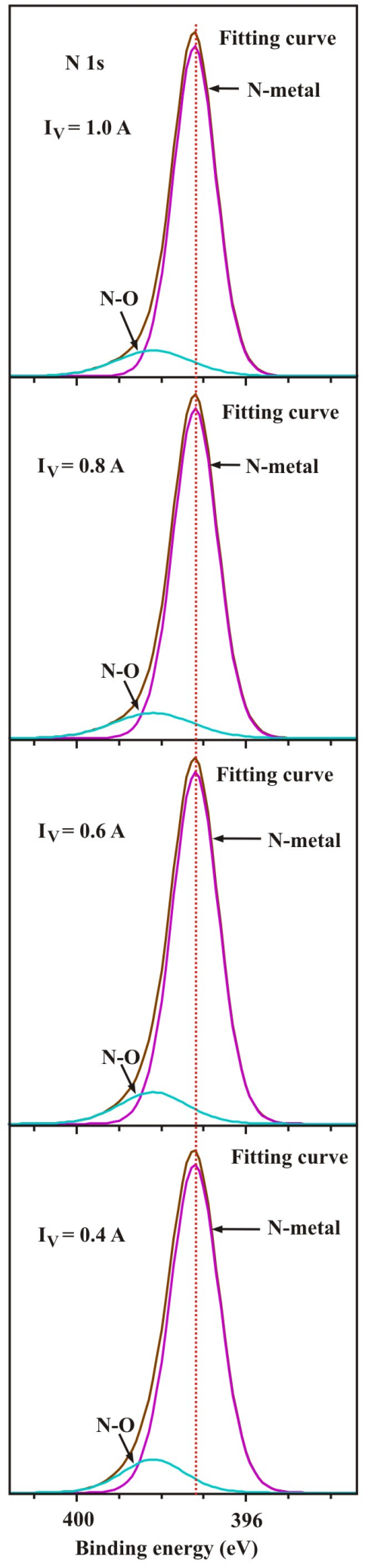

(c)

Figure 6. XPS deconvolution spectra of: (a) Ti $2 p_{3 / 2}$, (b) $V 2 p_{3 / 2}$ and (c) $N 1 s$. 
and $\mathrm{N}$ 1s of the TiVN films deposited at different V sputtering currents.

\subsection{Chemical State}

The binding energy (BE) of Ti $2 \mathrm{p}_{3 / 2}, \mathrm{~V} 2 \mathrm{p}_{3 / 2}$ and $\mathrm{N} 1 \mathrm{~s}$ peaks are summarized in Table 4. It was observed that the $\mathrm{BE}$ of $\mathrm{Ti} 2 \mathrm{p}_{3 / 2}$ and $\mathrm{V} 2 \mathrm{p}_{3 / 2}$ peaks shifted towards the higher $\mathrm{BE}$ as the $\mathrm{V}$ content in the film increased. This peak shift indicated that there was a change in the $\mathrm{Ti}$ and $\mathrm{V}$ bonds from pure Ti-Ti bonds to Ti-N bonds and from pure V-V bonds to V-N bonds as shown in Figure 6(a) and (b), respectively.

As shown in Figure 6, the $\mathrm{Ti} 2 \mathrm{p}_{3 / 2}$ and $\mathrm{V} 2 \mathrm{p}_{3 / 2}$ could be decomposed into four peaks while the $\mathrm{N} 1 \mathrm{~s}$ could be decomposed into two peaks. These peaks were compared with standard XPS database obtained from Ref. [23] and corresponding chemical bonds were assigned. Table 5 shows the BE of all peak positions and corresponding chemical bonds. The relative fraction of bonding type contributing to XPS spectra can be determined by calculating the area under the deconvoluted peaks and the results are summarized in Table 5. The plots between the bond fraction and V sputtering current are shown in Figure 7.

Considering the N-N and N-metal (N-Ti plus N-V) bonds obtained from the deconvolution of $\mathrm{N} 1 \mathrm{~s}$ spectra. It can be seen that the fraction of $\mathrm{N}-\mathrm{N}$ bonds decreased while that of $\mathrm{N}$-metal bonds increased with increasing $\mathrm{V}$ sputtering current. From Table 5 and Figure 7, pure Ti-Ti bond was observed only at $\mathrm{V}$ sputtering current, $\mathrm{I}_{\mathrm{V}}$ $=0.4 \mathrm{~A}$ and changed to $\mathrm{T}-\mathrm{N}$ bond as $\mathrm{I}_{\mathrm{V}}$ was increased. As a result, the $\mathrm{Ti} \mathrm{p}_{3 / 2}$ peak shifted from $453.85 \mathrm{eV}$ (Ti-Ti bonds) to the higher BE of 454.29-455.22 eV (T-N bonds). In addition, pure $\mathrm{V}-\mathrm{V}$ bond was observed at $\mathrm{I}_{\mathrm{V}}=0.4,0.6,0.8$ and $1.0 \mathrm{~A}$ and partly changed to $\mathrm{V}-\mathrm{N}$ bond at $\mathrm{I}_{\mathrm{V}}=0.8$ and $1.0 \mathrm{~A}$. Hence, the $\mathrm{V} 2 \mathrm{p}_{3 / 2}$ peak shifted from 512.15-512.61 eV (V-V bonds) to the higher BE of $514.29 \mathrm{eV}$ (V-N bonds).

As seen in Figures 6 and 7, a small fraction of V-N bond was observed only at high $\mathrm{V}$ sputtering currents of

Table 4. Binding energies of $\mathrm{Ti} 2 \mathrm{p}_{3 / 2}, \mathrm{~V} 2 \mathrm{p}_{3 / 2}$ and $\mathrm{N} 1 \mathrm{~s}$ core levels.

\begin{tabular}{cccc}
\hline $\mathrm{I}_{\mathrm{V}}(\mathrm{A})$ & $\mathrm{Ti} 2 \mathrm{p}_{3 / 2}$ & $\mathrm{~V} 2 \mathrm{p}_{3 / 2}$ & $\mathrm{~N} 1 \mathrm{~s}$ \\
\hline 0.4 & 454.24 & 512.18 & 396.20 \\
0.6 & 454.55 & 512.52 & 396.18 \\
0.8 & 454.70 & 512.67 & 396.22 \\
1.0 & 454.82 & 512.98 & 396.20 \\
\hline
\end{tabular}

Table 5. Binding energy positions and relative fractions of bonding types contributing to $\mathrm{Ti} 2 \mathrm{p}_{3 / 2}, \mathrm{~V} 2 \mathrm{p}_{3 / 2}$ and $\mathrm{N} 1 \mathrm{~s}$.

\begin{tabular}{|c|c|c|c|c|c|c|c|c|c|}
\hline \multicolumn{4}{|c|}{ Ti $2 p_{3 / 2}$} & \multicolumn{3}{|c|}{$\mathrm{V} 2 \mathrm{p}_{3 / 2}$} & \multicolumn{3}{|c|}{$\mathrm{N} 1 \mathrm{~s}$} \\
\hline $\mathrm{I}_{\mathrm{V}}(\mathrm{A})$ & $\begin{array}{c}\text { Peak } \\
\text { position }(\mathrm{eV})\end{array}$ & $\begin{array}{c}\text { Bond } \\
\text { assigned }\end{array}$ & $\begin{array}{c}\text { Bond } \\
\text { fraction }(\%)\end{array}$ & $\begin{array}{c}\text { Peak } \\
\text { Position }(\mathrm{eV})\end{array}$ & $\begin{array}{c}\text { Bond } \\
\text { assigned }\end{array}$ & $\begin{array}{c}\text { Bond } \\
\text { fraction }(\%)\end{array}$ & $\begin{array}{c}\text { Peak } \\
\text { position }(\mathrm{eV})\end{array}$ & $\begin{array}{c}\text { Bond } \\
\text { assigned }\end{array}$ & $\begin{array}{c}\text { Bond } \\
\text { fraction }(\%)\end{array}$ \\
\hline \multirow{4}{*}{0.4} & 453.85 & Ti-Ti & 12.66 & 512.15 & V-V & 14.39 & & & \\
\hline & 454.50 & Ti-N & 13.33 & 512.59 & $\mathrm{~V}-\mathrm{V}$ & 17.59 & 397.42 & N-metal & 88.23 \\
\hline & 455.86 & Ti-O & 32.00 & 513.15 & $\mathrm{~V}-\mathrm{O}$ & 5.37 & 398.20 & $\mathrm{~N}-\mathrm{O}$ & 11.77 \\
\hline & 457.80 & Ti-O & 12.93 & 514.85 & $\mathrm{~V}-\mathrm{O}$ & 31.19 & & & \\
\hline \multirow{4}{*}{0.6} & 454.33 & Ti-N & 8.42 & 512.15 & $\mathrm{~V}-\mathrm{V}$ & 9.54 & & & \\
\hline & 454.82 & Ti-N & 15.78 & 512.57 & $\mathrm{~V}-\mathrm{V}$ & 10.63 & 397.40 & N-metal & 88.47 \\
\hline & 455.94 & Ti-O & 35.31 & 513.11 & $\mathrm{~V}-\mathrm{O}$ & 16.36 & 398.17 & $\mathrm{~N}-\mathrm{O}$ & 11.53 \\
\hline & 458.30 & Ti-O & 11.92 & 514.87 & $\mathrm{~V}-\mathrm{O}$ & 35.73 & & & \\
\hline \multirow{4}{*}{0.8} & 454.29 & Ti-N & 11.70 & 512.59 & $\mathrm{~V}-\mathrm{V}$ & 11.62 & & & \\
\hline & 455.00 & Ti-N & 13.20 & 513.09 & $\mathrm{~V}-\mathrm{O}$ & 22.70 & 397.41 & $\mathrm{~N}$-metal & 88.06 \\
\hline & 455.89 & Ti-O & 26.47 & 514.29 & V-N & 3.82 & 398.09 & $\mathrm{~N}-\mathrm{O}$ & 11.94 \\
\hline & 457.82 & Ti-O & 18.43 & 514.89 & $\mathrm{~V}-\mathrm{O}$ & 31.07 & & & \\
\hline \multirow{4}{*}{1.0} & 454.50 & Ti-N & 13.46 & 512.61 & $\mathrm{~V}-\mathrm{V}$ & 11.75 & & & \\
\hline & 455.22 & Ti-N & 15.25 & 513.10 & $\mathrm{~V}-\mathrm{O}$ & 17.99 & 397.40 & $\mathrm{~N}$-metal & 87.89 \\
\hline & 456.80 & Ti-O & 38.41 & 514.28 & $\mathrm{~V}-\mathrm{N}$ & 5.02 & 398.03 & $\mathrm{~N}-\mathrm{O}$ & 12.11 \\
\hline & 458.51 & Ti-O & 4.14 & 514.89 & $\mathrm{~V}-\mathrm{O}$ & 34.83 & & & \\
\hline
\end{tabular}




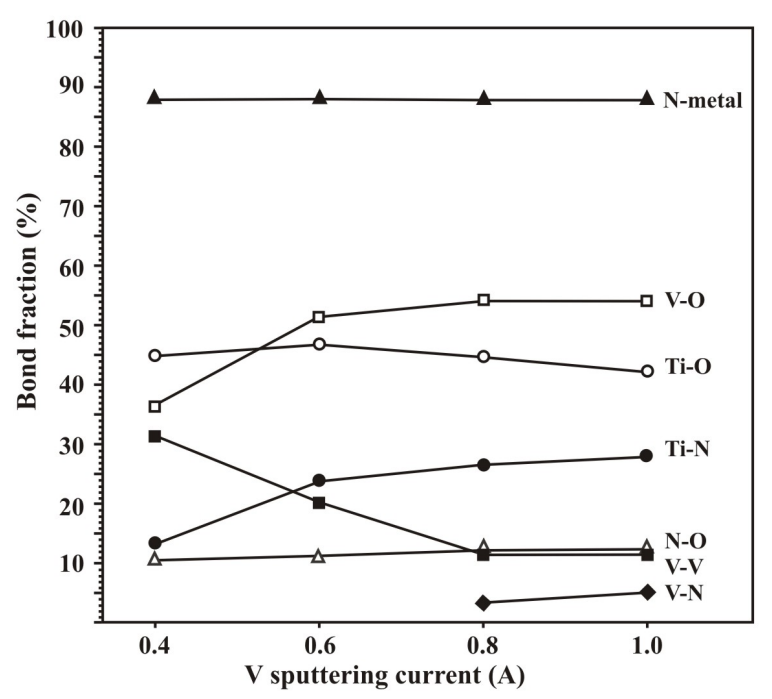

Figure 7. Relative bond fraction as a function of $\mathrm{V}$ sputtering current.

0.8 and 1.0 A. This result indicating that $\mathrm{V}$ atom has low affinity with $\mathrm{N}$ atom which is consistent with constant of $\mathrm{N}$ content in the films as shown in Table 3. Moreover, the summation of fractions of Ti-N and V-N bonds should be equal to the fraction of N-metal bonds. However, from Figure 7 the summation of Ti-N and V-N bond fractions is much less than that of N-metal. This is due to the bond fractions contributed from Ti $2 \mathrm{p}_{1 / 2}$ and $\mathrm{V}$ $2 p_{1 / 2}$ were not included in the bond fraction values as shows in Table 5. It is noted that the Ti-O and V-O bonds with rather high fraction can be observed for all the deposited TiVN films. This result confirms the presence of oxygen with high concentration of approximately 10 at.\% in all films as shown in Table 3.

\section{Conclusion}

TiVN films were successfully deposited on $\mathrm{Si}(100)$ wafers at room temperature by reactive dc magnetron cosputtering. The Ti sputtering current was fixed at $0.6 \mathrm{~A}$ whereas $\mathrm{V}$ sputtering current was varied from 0.4 to $1.0 \mathrm{~A}$. The effects of vanadium content on the structure and chemical state of the deposited films were investigated by XRD, FE-SEM and XPS. The XRD and XRS results revealed that all the prepared films formed $(\mathrm{Ti}, \mathrm{V}) \mathrm{N}$ solid solution. Furthermore, the deconvolution spectra of Ti $2 p$, $\mathrm{V} 2 \mathrm{p}$ and $\mathrm{N} 1 \mathrm{~s}$ revealed the type of bonding and the bond fraction in the films. This study led to more understanding of the structure and bonding type as vanadium content in TiVN films increased.

\section{Acknowledgements}

This work had partially been supported by Thailand Cen- tre of Excellent in Physics (ThEP), King Mongkut's University of Technology Thonburi under The National Research University Project and Vacuum Technology and Thin Films Research Laboratory, Burapha University.

\section{REFERENCES}

[1] K. H. Lee, C. H. Park, Y. S. Yoon and J. J. Lee, "Structure and Properties of $\left(\mathrm{Ti}_{1-\mathrm{x}} \mathrm{Cr}_{\mathrm{x}}\right) \mathrm{N}$ Coatings Produced by the Ion-Plating Method," Thin Solid Films, Vol. 385, No. 1, 2001, pp. 167-173. doi:10.1016/S0040-6090(00)01911-8

[2] G. S. Kim, B. S. Kim, S. Y. Lee and J. H. Hahn, "Structure and Mechanical Properties of Cr-Zr-N Films Synthesized by Closed Field Unbalanced Magnetron Sputtering with Vertical Magnetron Sources," Surface \& Coatings Technology, Vol. 200, No. 5-6, 2005, pp. 1669-1675. doi:10.1016/j.surfcoat.2005.08.101

[3] S. M. Aouadi, T. Maeruf, R. D. Twesten, D. M. Mihut and S. L. Rohde, "Physical and Mechanical Properties of Zirconium Nitride Thin Films," Surface \& Coatings Technology, Vol. 200, No. 11, 2006, pp. 3411-3417. doi:10.1016/j.surfcoat.2005.02.169

[4] H. Hasegawa, A. Kimura and T. Suzuki, "Microhardness and Structural Analysis of (TI,AI)N, (Ti,Cr)N, (Ti,Zr)N, and (TI,V)N, Films," Journal of Vacuum Science \& Technology A, Vol. 18, No. 3, 2000, pp. 1038-1040. doi:10.1116/1.582296

[5] R. Wuhrer and W. Y. Yeung, "Grain Refinement with Increasing Magnetron Discharge Power in Sputter Deposition of Nanostructured Titanium Nitride Coatings," Scripta Materialia, Vol. 50, No. 6, 2004, pp. 813-818. doi:10.1016/j.scriptamat.2003.12.022

[6] P. W. Shum, K. Y. Li, Z. F. Zhou and Y. G. Shen, "Structural and Mechanical Properties of Titanium-Aluminium Nitride Films Deposited by Reactive Close-Field Unbalanced Magnetron Sputtering," Surface \& Coatings Technology, Vol. 185, No. 2-3, 2004, pp. 245-253. doi:10.1016/j.surfcoat.2003.12.011

[7] O. Knotek, W. D. Munz and T. Keyendecker, "Industrial Deposition of Binary, Ternary, and Quarternary Nitrides of Titanium, Zirconium and Aluminum," Journal of Vacuum Science \&Technology A, Vol. 5, No. 4, 1987, pp. 2173-2179. doi:10.1116/1.574948

[8] N. Ichimiya, Y. Onishi and Y. Tanaka, "Properties and Cutting Performance of $(\mathrm{Ti}, \mathrm{V}) \mathrm{N}$ Coatings Prepared by Cathodic Arc Ion Plating," Surface \& Coatings Technology, Vol. 200, No. 5-6, 2005, pp. 1377-1382. doi:10.1016/j.surfcoat.2005.08.026

[9] S. Boelens and V. Veltrop, "Hard Coatings on TiN, (TiHf)N and (TiNb)N Deposited by Random and Steered Arc Evaporation," Surface \& Coatings Technology, Vol. 33, 1987, pp. 63-71. doi:10.1016/0257-8972(87)90177-0

[10] J. G. Han, H. S. Myung, H. M. Lee and L. R. Shaginyan, "Microstructure and Mechanical Properties of Ti-Ag-N 
and Ti-Cr-N Superhard Nanostructured Coatings," Surface \& Coatings Technology, Vol. 174-175, 2003, pp. 738-743. doi:10.1016/S0257-8972(03)00565-6

[11] D. H. Jung, H. S. Park, H. D. Na, J. W. Lim, J. J. Lee and J. H. Joo, "Mechanical Properties of (Ti,Cr)N Coatings Deposited by Inductively Coupled Plasma Assisted Direct Current Magnetron Sputtering," Surface \& Coatings Technology, Vol. 169-170, 2003, pp. 424-427. doi:10.1016/S0257-8972(03)00146-4

[12] S. M. Aouadi, K. C. Wong, K. A. R. Mitchell, F. Namavar, E. Tobin, D. M. Mihut and S. L. Rohde, "Characterization of Titanium Chromium Nitride Nanocomposite Protective Coatings," Applied Surface Science, Vol. 229, No. 1-4, 2004, pp. 387-394. doi:10.1016/j.apsusc.2004.02.019

[13] V. M. Vishnyakov, V. I. Bachurin, K. F. Minnebaev, R. Valizadeh, D. G. Teer, J. S. Colligon, V. V. Vishnyakov and V. E. Yurasova, "Ion Assisted Deposition of Titanium Chromium Nitride," Thin Solid Films, Vol. 497, No. 1-2, 2006, pp. 189-195. doi:10.1016/j.tsf.2005.05.005

[14] R. Sanjines, O. Banakh, C. Rojas, P. E. Schmid and F. Levy, "Electronic Properties of $\mathrm{Cr}_{1-\mathrm{x}} \mathrm{Al}_{\mathrm{x}} \mathrm{N}$ Thin Films Deposited by Reactive Magnetron Sputtering," Thin Solid Films, Vol. 420-421, 2002, pp. 312-317. doi:10.1016/S0040-6090(02)00830-1

[15] M. Uchida, N. Nihira, A. Mitsuo, K. Toyoda, K. Kubota and T. Aizawa, "Friction and Wear Properties of CrAlN and CrVN Films Deposited by Cathodic Arc Ion Plating Method," Surface \& Coatings Technology, Vol. 177-178, 2004, pp. 627-630. doi:10.1016/S0257-8972(03)00937-X

[16] W. Y. Yeung, S. N. Dub, R. Wuhrer and Y. V. Milman, "A Nanoindenation Study of Magnetron Co-Sputtered Nanocrystalline Ternary Nitride Coatings," Science of Sintering, Vol. 38, No. 3, 2006, pp. 211-221. doi:10.2298/SOS0603211Y
[17] L. Wang, G. Zhang, R. J. K. Wood, S. C. Wang and Q. Xue, "Fabrication of CrAlN Nanocomposited Films with High Hardness and Excellent Anti-Wear Performance for Gear Application," Surface \& Coatings Technology, Vol. 204, No. 21-22, 2010, pp. 3517-3524. doi:10.1016/j.surfcoat.2010.04.014

[18] H. Hasegawa, M. Kawate and T. Suzuki, "Effects of Al Contents on Microstructures of $\mathrm{Cr}_{1-\mathrm{x}} \mathrm{Al}_{\mathrm{x}} \mathrm{N}$ and $\mathrm{Zr}_{1-\mathrm{x}} \mathrm{Al}_{\mathrm{x}} \mathrm{n}$ Films Synthesized by Cathodic Arc Method," Surface \& Coatings Technology, Vol. 200, No. 7, 2005, pp. 24092413. doi:10.1016/j.surfcoat.2004.08.208

[19] E. Martinez, R. Sanjines, A. Karimi, J. Esteve and F. Levy, "Mechanical Properties of Nanocomposite and Multilayered Cr-Si-N Sputtered Films," Surface \& Coatings Technology, Vol. 180-181, No. 6, 2004, pp. 570-574. doi:10.1016/j.surfcoat.2003.10.121

[20] P. Hones, M. Diserens, R. Sanjines and F. Levy, "Electronic Structure and Mechanical Properties of Hard Coating Chromium-Tungsten Nitride System," Journal of Vacuum Science and Technology B, Vol. 18, No. 6, 2000, pp. 2851-2856. doi:10.1116/1.1320806

[21] U. Konig, "Deposition and Properties of Multicomponent Hard Coatings," Surface \& Coatings Technology, Vol. 33, 1987, pp. 91-103. doi:10.1016/0257-8972(87)90180-0

[22] A. Cavaleiro, B. Trindade and M. T. Vieira, "The Influence of the Addition of a Third Element on the Structure and Mechanical Properties of Transition-Metal-Based Nanostructured Hard Films: Part I-Nitrides," In: A. Cavaleiro and J. Th. M. De Hosson, Eds., Nanostructured Coatings, Springer, New York, 2006, pp. 261-314.

[23] C. J. Powell, "NIST XPS Datebase, Elecment Composition Search Menu," 2012.

http:/srdata.nist.gov/xps/elmcomposition.aspx. 